\title{
On Growth and Chemistry of Electrodeposited Mg Layers with Electrolytes Having Varying Cl Content for Battery Application
}

Mukesh Bachhav ${ }^{1}$, Emily Nelson ${ }^{2}$, Adam Crowe ${ }^{2}$, Bart Bartlett ${ }^{2}$, Nathan $\mathrm{Hahn}^{3}$, Kevin Zavadil ${ }^{3}$, PengWei Chu ${ }^{1}$, Emmanuelle A. Marquis ${ }^{1}$

${ }^{1 .}$ Department of Materials Science and Engineering, University of Michigan, Ann Arbor, MI, USA

2. Department of Chemistry, University of Michigan, Ann Arbor, MI, USA

3. Advanced Materials Laboratory, Sandia National Laboratories, Albuquerque, NM, USA

There is increasing interest in finding alternative solutions to $\mathrm{Li}$ based batteries due to its high cost, safety issues, and sensitivity to high temperatures. Among alternative materials, Mg-based batteries are promising candidates due to magnesium metal's low cost, environmentally benignity, high theoretical specific charge capacity $(2.205 \mathrm{Ah} / \mathrm{g})$, and high theoretical energy density $\left(3.8 \mathrm{Ah} / \mathrm{cm}^{3}\right)[1]$. A major challenge in the application of rechargeable $\mathrm{Mg}$ batteries is the development of a suitable electrolyte that is compatible with a $\mathrm{Mg}$ anode and a high voltage/capacity cathode. In this study, atom probe tomography (APT) and transmission electron microscopy (TEM) have been successfully applied to elucidate the differences in $\mathrm{Mg}$ growth from a series of $\mathrm{Mg}$-based electrolytes.

We examine the structure and chemistry of $\mathrm{Mg}$ electrodeposited with different electrolytes, namely magnesium aluminum chloride complex (MACC) [2], magnesium trifluoromethane imide (TFSI) [3] and magnesium triphenoxyaluminate (MTPA) [4], that were selected for their different chloride contents. The MACC electrolyte $\left(\mathrm{MgCl}_{2}+\mathrm{AlCl}_{3}\right)$ has a high $\mathrm{Cl}$ content compared to MTPA $\left(\mathrm{PhMgCl}+\mathrm{Al}(\mathrm{OPh})_{3}\right.$ in 4:1 ratio) while the conventional TFSI $\left(\mathrm{Mg}\left[\mathrm{N}-\left(\mathrm{SO}_{2} \mathrm{CF}_{3}\right)_{2}\right]_{2}\right)$ electrolyte has no $\mathrm{Cl}$ content. Analysis of the chemistry of the Mg deposits showed a strong dependency on the electrolyte and its conditioning. Conditioned MACC and MTPA with a cycling efficiency of $99 \%$ yielded 99.5 at. $\%$ pure $\mathrm{Mg}$ whereas TFSI with a $80 \%$ cycling efficiency yielded 98.5 at. \% pure $\mathrm{Mg}$. $\mathrm{Mg}$ impurities such as $\mathrm{Mg}-\mathrm{O}, \mathrm{Mg}-\mathrm{H}, \mathrm{Mg}-\mathrm{OH}, \mathrm{Mg}-\mathrm{C}$ tend to be distributed along lines perpendicular to $<001>$ direction in the Mg crystals deposited using TFSI or with unconditioned MTPA electrolytes, implying that impurity adsorption and/or reaction is facet-dependent and directs the growth structure of $\mathrm{Mg}$. (Distribution of impurities is shown in Fig. 1a-c)

The nucleation and growth mechanism of $\mathrm{Mg}$ grains during deposition of $\mathrm{Mg}$ onto its own interface is important to understand the long-term stability of rechargeable $\mathrm{Mg}$ batteries operated under realistic conditions. To investigate the interactions with possible surface films, analyses were carried out on $\mathrm{Mg}$ layers, for which deposition had been interrupted for some controlled amount of time to let the surface equilibrate with the electrolyte. A TEM cross-section image (Fig. 2a-b) illustrates the two layers of $\mathrm{Mg}$ formed during the interrupted deposition (30 mins) using MACC. APT analysis indicates the presence of $\mathrm{C}, \mathrm{Al}$, and $\mathrm{Mg}$ oxides/hydrides at the interface (Fig. 2c-d). Also, TEM diffraction taken across the interface indicates change in orientation of $\mathrm{Mg}$ crystal suggesting re-nucleation at the interface. Our understanding of the role of the surface film in governing the re-nucleation of $\mathrm{Mg}$ onto itself will be discussed in this presentation [5].

References:

[1] H Yoo et al, Energy \& Environmental Science 6, (2013), p. 2265. 
[2] C Barile et al, The Journal of Physical Chemistry C 118, (2014), p. 27623.

[3] S Lapidus et al, Physical Chemistry Chemical Physics 16, (2014), p. 21941.

[4] E Nelson et al, Journal of Materials Chemistry A 2 (2014), p. 18194.

[5] This work was supported by the Joint Center for Energy Storage Research (JCESR), an Energy Innovation Hub funded by the U. S Department of Energy, Office of Science, Basic Energy Sciences, the University of Michigan College of Engineering, and the Michigan Center for Materials Characterization.

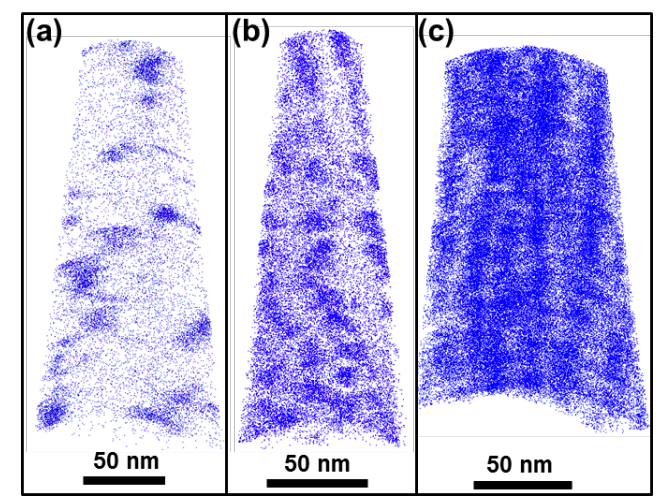

Figure 1: 3D distribution of impurities (Mg-O, $\mathrm{Mg}-\mathrm{H}, \mathrm{Mg}-\mathrm{OH}, \mathrm{Mg}-\mathrm{C}$ ) in $\mathrm{Mg}$ matrix for (a) MACC (b) MTPA and (c) TFSI electrolyte.
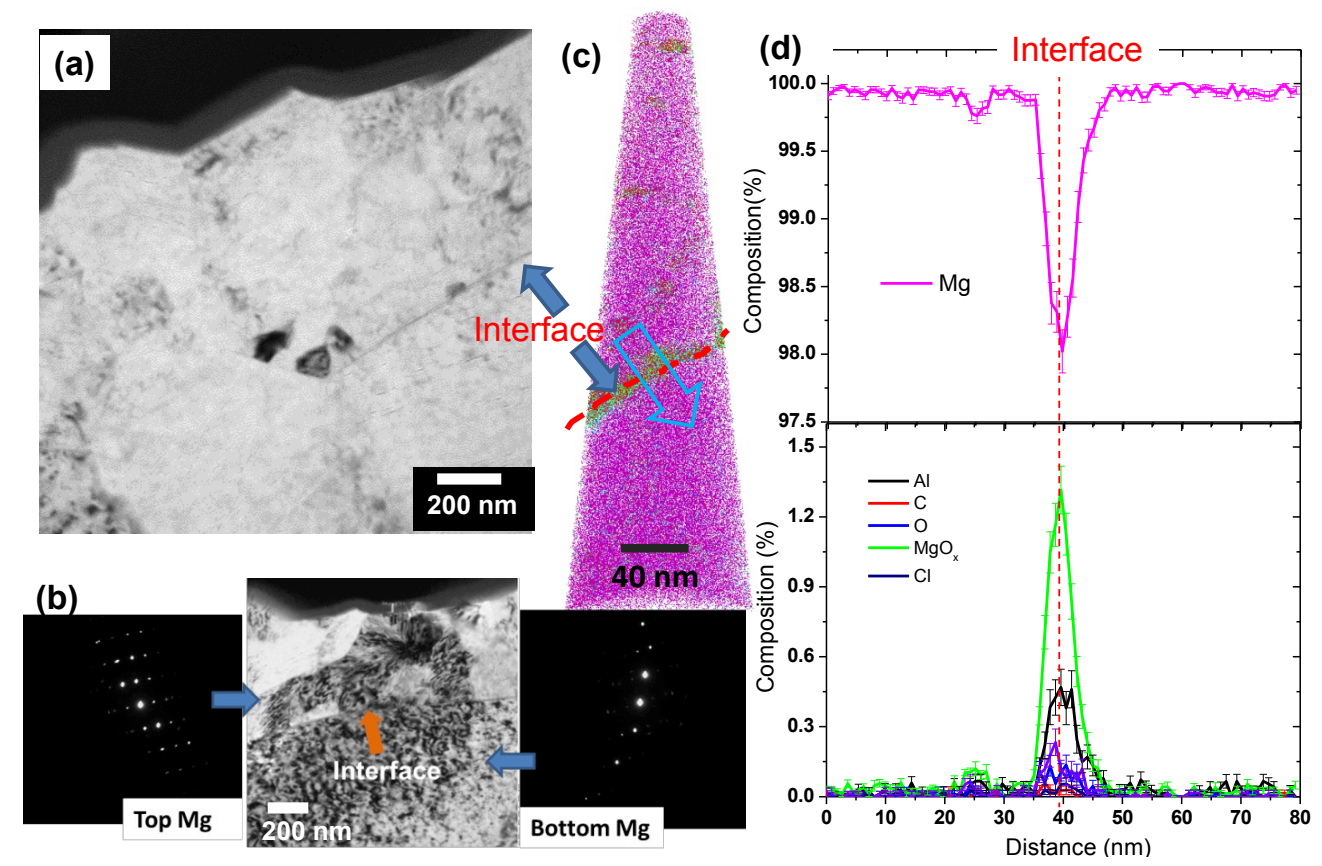

Figure 2: (a) TEM image of Mg layers separated by faint line at interface. (b) Diffraction pattern taken across interface. (c) 3-D reconstruction showing interface and distribution of $\mathrm{Mg}$ and $\mathrm{Mg}$-complexes. (d) Distribution profile taken across interface for $\mathrm{Mg}$ and $\mathrm{Mg}$-complexes shown by arrow in (c) 